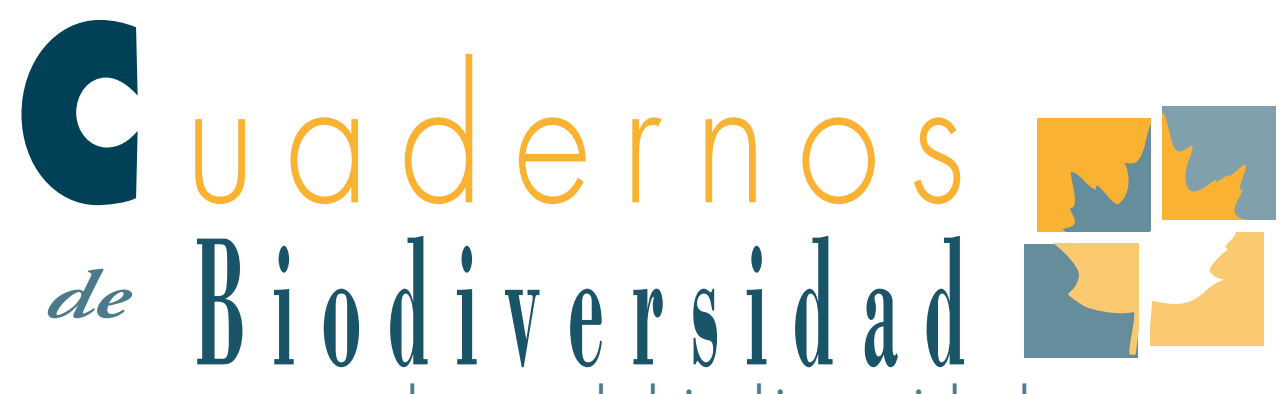

www. cuadernosdebiodiversidad.org

\title{
Ni bueno, ni bonito, ni barato El problema de la simplificación de la naturaleza
}

\section{G. J. Souba Dols}

Máster en Biodiversidad y Conservación, Universidad de Alicante. Alicante, España. E-MAIL: GJS.DOLS@GMAIL.COM

\section{ABSTRACT}

Modern society has lost its natural connection with the environment. Present agriculture methods and city planning around the world support this fact. Humanity has always simplified nature in order to control it but, far from this, we have contributed to enhance current environmental issues as air and water pollution, soil fertility loss, species extinction and climate change. Therefore, it may be reasonable to change our point of view of nature. By assuming that we are an inseparable part of nature and vice versa, we may achieve a true conservation of the richness of our planet. We must synthesise nature because every living being is a part of a bigger whole.
We need to live the complexity of life. Nowadays, we have reached a turning point after which we must decide either changing our ways or sacrificing our future. Hopefully, a slight impulse is sometimes enough to change the course of History.

\section{KEY WORDS:}

Simplification of nature, synthesis, modern society, urban ecosystem, agriculture, human-nature connection, turning point, climate change. 
Desde que el hombre es hombre, nuestra especie ha usado todos recursos que ha podido encontrar en la Tierra. Desde los más pequeños frutos del bosque, hasta las cacerías de mamuts y grandes bisontes en el lejano Oeste; desde las paradisiacas playas del trópico hasta los páramos helados de Eurasia. Y es que el ser humano ha demostrado que es capaz de adaptarse a casi todo lo que se le venga encima. En los dos últimos siglos, las sociedades han vivido profundos cambios sociales, culturales y económicos que han traído grandes avances, y grandes problemas. Uno de estos problemas son las plagas que provocan pérdidas económicas que combatimos con plaguicidas que causan a su vez importantes pérdidas de biodiversidad, tanto en los ecosistemas agrícolas como en los forestales. El suelo se empobrece y se reducen las cosechas, mientras los fertilizantes contaminan el agua que bebemos y finalmente llegan al mar por los ríos. Las especies se desplazan de donde siempre han estado para ocupar nuevos espacios en los que ocasionan nuevos problemas. Y el cambio climático global es una evidencia de todo esto. Seamos conscientes. Los problemas ambientales derivados de nuestras actividades individuales afectan a la riqueza del planeta y, para quien todavía no se haya dado cuenta, a toda la humanidad. Pensando un poco sobre esto, uno llega a la conclusión de que hemos perdido una buena parte de nuestra conexión con la naturaleza. No somos capaces de ponernos en la piel de nuestros vecinos, y mucho menos en la de otros seres vivos que nos acompańan y nos prestan múltiples servicios vitales cada día. Por poner un ejemplo, si no fuera por las abejas y su incesante trabajo en las flores hoy no estaríamos aquí.

Y ahí no queda la cosa. Las consecuencias de la simplificación de la naturaleza y del paisaje es fundamental para poder entender nuestros problemas actuales. Para producir más y mejor, lo hacemos mediante extensos monocultivos de variedades únicas seleccionadas, simplificando la biodiversidad de los agroecosistemas hasta la mínima expresión además de, simplificarlo también por el uso de plaguicidas, fertilizantes y otra serie de insumos agrícolas. Sólo excepcionalmente se tiene en cuenta a los insectos y a las plantas que de ellos dependen. Esto no es bueno, ni bonito, ni barato. Pero no piense que esta simplificación es ajena a su sofá. ¿Cuántos y cuán variados son los parques de su ciudad? ¿Hay árboles y flores suficientes para usted? ¿Y para los pájaros y abejas que viven de ellos? Las golondrinas tan famosas de Becquer sólo volverán cada año si tienen qué comer. Esos diminutos insectos voladores que menospreciamos incluso antes de que aparezcan. Desgraciadamente, esto también es simplificar.

Para clarificar el asunto, déjeme emplear algo de lo que sé de cocina. El manual del buen cocinero aconseja empezar de abajo a arriba, como en casi todas las cosas de la vida, de lo simple a lo complejo. Sin embargo, las más simples recetas ambientales en el campo y la ciudad no nos han dado buen resultado. ¿Sería una locura cambiar la estrategia y pasar a las recetas más elaboradas? Quizá obtengamos mejores resultados y nunca antes las hayamos probado por miedo a destrozar el pastel. Y a mí, que me gusta cocinar, no hay receta compleja que me parezca imposible preparar. Sólo hace falta añadir los ingredientes en su adecuada medida y armonía para que el guiso provoque las más variadas sensaciones al paladar. ¿`Y si imitáramos a la naturaleza? ¿Y si construyéramos nuestros campos y ciudades pensando en que naturaleza y hombre son una única cosa? No piense que esto es imposible. Ya se hace. El control biológico de plagas es una realidad. Observando el "quien se come a quien" se puede reducir en gran parte el uso de químicos agrícolas para que todos podamos disfrutar y beneficiarnos de alimentos mas sanos.

La simplificación de la naturaleza es una cuestión de concepto. Y cuando hay conceptos de por medio son necesarias las definiciones. La RAE la describe como la acción o efecto de simplificar, que es lo mismo que hacer más sencillo, más fácil o menos complicado algo. Esto es lo que hemos venido haciendo, reducir la naturaleza para que sea más fácil de controlar y de manejar. Pero no lo hemos logrado. Desde mi punto de vista, la palabra síntesis es mucho más adecuada para lo que aquí tratamos: composición de un todo por la reunión de sus partes o la suma y compendio de una materia u otra cosa. Y es que debemos sintetizar, y no simplificar, la naturaleza en la que vivimos. Admirar y vivir la 
grandeza y la complejidad de la Naturaleza donde jugamos un papel fundamental y desde luego, el de mayor responsabilidad. Y un gran ejemplo de esto son las milpas mexicanas, cultivos en los que se imita la complejidad de la vida, cultivando unas plantas sobre los restos de otras, aprovechando los beneficios de las relaciones entre las plantas y los insectos. Y en las ciudades también hay ejemplos de que esto es posible como el de los municipios franceses que compiten cada primavera para premiar a la villa más florida y respetuosa con el medio ambiente, cosa que aprovechan las abejas para darse un festín.

El momento que nos ha tocado vivir en la actualidad es un punto de inflexión en la historia de la humanidad. O así lo veo yo. Debemos decidir hacia dónde queremos ir y lo que no estamos dispuestos a sacrificar. Si nos quedamos con lo simple, o empezamos a sintetizar. No es posible seguir desvinculados de la naturaleza por más tiempo porque no ser conscientes de los problemas ambientales que generamos es de una ingenuidad cobarde y no soluciona el problema. A veces una pequeña acción basta para cambiar el rumbo de la cosas. Yo recuerdo con claridad mi primera vez sobre una bicicleta. Estaba aterrado y mi cuerpo no se movía. Fue mi padre quien me dio el empujón que necesitaba para comenzar a pedalear. Tembloroso, conseguí enderezar el manillar y mantener el equilibrio para seguir hacia adelante superando mi miedo a caer. Y claro, la sensación que vino después, bueno, seguro que la conoce. 